This item was submitted to Loughborough's Research Repository by the author.

Items in Figshare are protected by copyright, with all rights reserved, unless otherwise indicated.

\title{
Exercise and coronary heart disease risk markers in South Asian and
}

\section{European men}

PLEASE CITE THE PUBLISHED VERSION

http://dx.doi.org/10.1249/MSS.0b013e3182853ecf

PUBLISHER

(C) American College of Sports Medicine

VERSION

AM (Accepted Manuscript)

LICENCE

CC BY-NC-ND 4.0

\section{REPOSITORY RECORD}

Arjunan, Saravana P., Nicolette Bishop, Alvaro Reischak-Oliveira, and David J. Stensel. 2019. "Exercise and Coronary Heart Disease Risk Markers in South Asian and European Men". figshare.

https://hdl.handle.net/2134/15529. 
This item was submitted to Loughborough's Institutional Repository (https://dspace.lboro.ac.uk/) by the author and is made available under the following Creative Commons Licence conditions.

\section{creative
commons}

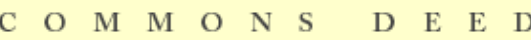

Attribution-NonCommercial-NoDerivs 2.5

You are free:

- to copy, distribute, display, and perform the work

Under the following conditions:

Attribution. You must attribute the work in the manner specified b the author or licensor.

Noncommercial. You may not use this work for commercial purposes.

No Derivative Works. You may not alter, transform, or build upon this work.

- For any reuse or distribution, you must make clear to others the license terms of this work.

- Any of these conditions can be waived if you get permission from the copyright holder.

Your fair use and other rights are in no way affected by the above.

This is a human-readable summary of the Leqal Code (the full license).

\section{Disclaimer 만}

For the full text of this licence, please go to: http://creativecommons.org/licenses/by-nc-nd/2.5/ 


\section{Medicine \& Science in Sports \& Exercise \\ Exercise and coronary heart disease risk markers in South Asian and European men. --Manuscript Draft--}

\begin{tabular}{|c|c|}
\hline Manuscript Number: & MSSE-D-12-00908R1 \\
\hline Full Title: & Exercise and coronary heart disease risk markers in South Asian and European men. \\
\hline Article Type: & Original Investigation \\
\hline Corresponding Author: & $\begin{array}{l}\text { David John Stensel, PhD } \\
\text { Loughborough University } \\
\text { Loughborough, Leicestershire UNITED KINGDOM }\end{array}$ \\
\hline Corresponding Author's Institution: & Loughborough University \\
\hline \multicolumn{2}{|l|}{$\begin{array}{l}\text { Corresponding Author's Secondary } \\
\text { Institution: }\end{array}$} \\
\hline \multirow[t]{4}{*}{ Order of Authors: } & Saravana Pillai Arjunan, BSc (Hons) \\
\hline & Nicolette Claire Bishop, PhD \\
\hline & Alvaro Reischak-Oliveira, PhD \\
\hline & David John Stensel, PhD \\
\hline
\end{tabular}




\section{Exercise and coronary heart disease risk markers in South Asian and European men.}

Saravana Pillai Arjunan, BSc, ${ }^{1}$ Nicolette C.Bishop, PHD,${ }^{1}$ Alvaro Reischak-Oliveira, PHD, ${ }^{2}$ and David J. Stensel, PHD ${ }^{1}$

${ }^{1}$ School of Sport, Exercise and Health Sciences, Loughborough University, Leicestershire, United Kingdom

${ }^{2}$ School of Physical Education, Federal University of Rio Grande do Sul - UFRGS, Porto Alegre - RS, Brazil

\section{Running Head}

Exercise and CHD risk markers in South Asians

\section{Correspondence}

Dr David Stensel

School of Sport, Exercise and Health Sciences

Loughborough University,

Leicestershire

LE11 3TU

United Kingdom

Phone: $+44(0) 1509226344$

Fax: +44(0)1509 226301

E-mail: D.J.Stensel@lboro.ac.uk

The research was supported by the National Institute for Health Research (NIHR) Diet, Lifestyle \& Physical Activity Biomedical Research Unit based at University Hospitals of Leicester and Loughborough University. The views expressed are those of the authors and not necessarily those of the NHS, the NIHR or the Department of Health. Professor ReischakOliveira received funding from the Brazilian National Research Council (CNPq).

The authors have no financial, consultant, institutional, or other relationships that might lead to bias or a conflict of interest. 


\begin{abstract}
Purpose: South Asians have a higher than average risk of coronary heart disease. The reasons for this are unclear but physical inactivity and/or poor responsiveness to exercise may play a role. This study compared the effect of prior exercise on postprandial triacylglycerol (TAG), glucose, insulin, interleukin-6 (IL-6) and soluble intercellular adhesion molecule-1 (sICAM-1) concentrations in South Asian and European men.
\end{abstract}

Methods: Ten healthy South Asian men (i.e. nine Indian men and one Pakistani man) and 10 healthy European men aged 20 to 28 years completed two, 2-day trials (exercise and control) in a randomised-crossover design. On the afternoon of day 1 of the exercise trial, participants ran on a treadmill for 60 minutes at approximately $70 \%$ of maximal oxygen uptake.

Participants rested on day 1 of the control trial. On day 2 of both trials participants rested and consumed high fat (57\% of energy content) test meals for breakfast $(0 \mathrm{~h})$ and lunch $(4 \mathrm{~h})$.

Fourteen venous blood samples were collected from a cannula between $0 \mathrm{~h}$ and $9 \mathrm{~h}$ for metabolic measurements.

Results: Three-way ANOVA identified higher $(P<0.05)$ postprandial TAG and insulin concentrations in South Asian versus European men. Exercise lowered postprandial TAG and IL-6 and elevated sICAM-1 concentrations. An interaction effect indicated a greater decrease (22 versus $10 \%$ ) in TAG area under the concentration versus time curve after exercise in South Asian than European men.

Conclusions: Postprandial TAG and insulin responses to high fat meals were elevated in these South Asian men but acute exercise was equally if not more effective for reducing postprandial lipemia in South Asian than in European men.

KEYWORDS: CARDIOVASCULAR DISEASE, EXERCISE, INFLAMMATION, PHYSICAL ACTIVITY, POSTPRANDIAL LIPEMIA 


\section{INTRODUCTION}

Paragraph number 1 Coronary heart disease (CHD) is responsible for more deaths in the UK (24), the USA (22), and globally (33) than any other single cause and prevention and treatment of CHD remain a public health priority. The prevalence of CHD varies among nations and ethnic groups and one group who are particularly susceptible are South Asians; a heterogeneous group originating from the Indian sub-continent e.g. India, Pakistan, Bangladesh, Sri Lanka and Nepal. Possibly the first to highlight this issue were Danaraj and colleagues (4) who reported a relatively high prevalence of CHD among Indian compared with Chinese people living in Singapore. More recent reports have confirmed high prevalence rates of CHD among South Asians living in the UK (30), the USA (17) and Canada (25) and estimates suggest a three to five fold increased risk of myocardial infarction and cardiovascular death among migrant South Asians compared with other ethnic groups (7).

Paragraph number 2 A variety of interacting factors may explain the elevated risk of CHD in South Asians and one of these is physical inactivity. In their review of physical activity levels among South Asians living in the UK Fischbacher and colleagues (8) identifed 12 studies in adults and five in children all of which reported lower levels of physical activity among UK South Asians than the general population. These findings have since been confirmed by data from a diabetes screening programme in Leicester, UK (34) and by the Health Survey for England (31). Moreover, it has been estimated that physical inactivity explains $>20 \%$ of the excess CHD mortality experienced by UK South Asians even after adjustment for potential confounders including socioeconomic status, smoking, diabetes and existing cardiovascular disease (CVD) (32). Outside of the UK the INTERHEART study found that only $6.1 \%$ of South Asians reported participation in moderate- or high-intensity exercise compared with $21.6 \%$ of participants from other countries (12). In light of such 
findings consensus physical activity guidelines for Asian Indians have recently been published in an attempt to promote physical activity among this group (15).

Paragraph number 3 Despite the high prevalence of CHD and low levels of physical activity among South Asians few studies have examined the effects of physical activity/exercise on CHD or on risk factors for CHD in this group although observational evidence suggests a protective role (20). Hence the purpose of the present study was to compare the effects of a single bout of exercise on CHD risk markers in those of South Asian (predominantly Indian) versus White European descent. The primary outcome variable in this study was postprandial triacylglycerol concentration, an established CHD risk factor (16) which is frequently reported to be lowered by acute bouts of exercise (13). Several other disease risk markers were examined in this study including total cholesterol, high density lipoprotein (HDL) cholesterol, glucose, insulin, interleukin-6 (IL-6) and soluble intercellular adhesion molecule-1 (sICAM-1). 


\section{METHODS}

Paragraph number 4 Participants. With the approval of Loughborough University's Ethics Advisory Committee 10 South Asian men and 10 men of White European descent were recruited and they gave their written informed consent to participate in this study. G Power (version 3.1.3, Franz Faul, Universitat Kiel, Germany) was used to calculate the study sample size and this indicated that 10 participants per group would be sufficient to detect a difference in TAG (the primary outcome variable) with a power of 0.75 and a $5 \%$ level of significance. Participants were healthy and recreationally active and ranged in age from 20 to 28 years. Participants were non-smokers, with no personal history of CVD or metabolic disease, and none of them reported taking medication. Participants had a BMI $<30 \mathrm{~kg} \cdot \mathrm{m}^{-2}$ and blood pressure $<140 / 90 \mathrm{~mm} \mathrm{Hg}$. Participants were not dieting and did not have any extreme dietary habits. To verify ethnicity each South Asian participant completed a form providing details of their place and country of birth, their mother tongue language, their religion and race, the country of their parents' birth and their family history of migration. This revealed that seven of the participants were Indian nationals, two were UK Indians and one was from Pakistan. All of the European participants were White with White parents and all were British citizens. All of the participants (South Asian and European) were students (some undergraduate, some postgraduate) studying at Loughborough University. Most of the European participants had lived in the UK for all of their lives while most of the South Asian participants had been living in the UK for less than two years.

Paragraph number 5 Anthropometry. Prior to the main trials participants attended the laboratory for a screening and familiarization visit lasting approximately two hours. During this visit they completed a participant information form and questionnaires assessing health status, usual physical activity and ethnicity (South Asians only). Subsequently, weight was 
measured to the nearest $0.01 \mathrm{~kg}$ using a digital scale (Seca Ltd, Germany) and height was measured to the nearest $0.1 \mathrm{~cm}$ using a stadiometer (Avery Industrial Ltd, Leicester, UK). Skinfold thickness was measured with calipers (Harpenden, Burgess Hill, U.K.) on the right hand side of the body at the biceps, triceps, subscapular and suprailliac. The sum of these four skinfold measurements was used to determine body density (6) and body fat percentage (26). In addition, waist circumference was determined at the narrowest part of the torso above the umbilicus and below the xiphoid process using a measuring tape. Lastly, blood pressure was measured using a digital monitor (Omron M5-1, Matsusaka Co., Ltd, Japan).

Paragraph number 6 Preliminary tests. After familiarization with motorized treadmill running (RUNRACE, Techno gym, Gambettola, Italy) participants completed two preliminary exercise tests: a submaximal, incremental treadmill running test (to determine the relationship between running speed and oxygen uptake) and a maximal oxygen uptake ( $\dot{\mathrm{VO}}_{2} \max$ ) test. The submaximal test was performed on a level treadmill and involved four, four-minute stages of increasing intensity. Initial running speed was set between 6 and 9.5 $\mathrm{km} \cdot \mathrm{h}^{-1}$ and the speed was increased by 0.5 or $1 \mathrm{~km} \cdot \mathrm{h}^{-1}$ (depending on each participant's level of fitness) at the end of each stage. After a 30 minute recovery, $\dot{\mathrm{VO}}_{2} \max$ was determined with the use of an incremental uphill protocol at a constant speed until participants reached volitional exhaustion (27). The initial treadmill gradient was set at 3.5\% for this test and the gradient was increased by $2.5 \%$ every 3 minutes. Short range telemetry (Sports tester $\mathrm{PE}_{3000}$, Polar Electro, Finland) was used to evaluate heart rate throughout both tests. Ratings of perceived exertion (RPE) were assessed periodically during these tests using the Borg scale (2). 
Paragraph number 7 Expired air samples were collected into Douglas bags (Plysu Protection Systems, Milton Keynes, United Kingdom) during both of the preliminary exercise tests. An $\mathrm{O}_{2} / \mathrm{CO}_{2}$ analyser (Servomex 1440, Crowborough, Sussex, United Kingdom) was used to measure the oxygen and carbon dioxide percentages within the expired air samples. The analysers were calibrated using gases of known concentration prior to testing. A dry gas meter (Harvard Apparatus, Edenbridge, United Kingdom) was used to measure expired air volumes which were corrected to standard temperature and pressure dry. The oxygen consumption values from the two preliminary exercise tests were used together to determine the running speed required to elicit $70 \%$ of each participant's $\mathrm{V}_{2} \max$.

Paragraph number 8 Main trials Participants completed two, two day trials (exercise and control) in a random order separated by an interval of at least one week. Trials were undertaken in block random order (block size of two) using software available at http://www.randomization.com/. The lead author (S.P.Arjunan) enrolled participants and assigned them to their trials. The lead author also supervised all of the data collection. On day one of the exercise trial, participants arrived at the laboratory between 8.00 and 9.00 am and rested (reading, working at a computer, watching television, listening to music or playing video games) throughout the day until $5.00 \mathrm{pm}$. Participants consumed a standardized lunch at approximately $12.00 \mathrm{pm}$ containing white bread, chocolate spread, butter, whole fat milk, chocolate muffin, apple, pear and water. At $3.30 \mathrm{pm}$, participants performed a 60 minute run at a speed predicted to elicit $70 \%$ of their $\dot{\mathrm{VO}}_{2} \max$. One minute samples of expired air were collected at 15 minute intervals during the run to monitor the exercise intensity i.e. minutes $14-15,29-30,44-45$ and 59-60 during the run. If necessary adjustments were made to the treadmill speed to ensure that participants were at the correct intensity. Heart rate and RPE were also monitored during the run. During day one of the control trial procedures were 
exactly the same as on day one of the exercise trial except that no running was performed and four, five-minute resting expired air samples were collected at the time when running was performed on day 1 of the exercise trial. Oxygen consumption and carbon dioxide production were calculated from expired air samples as described previously. Energy expenditure was estimated from oxygen consumption and carbon dioxide production values using stoichiometric equations (9).

Paragraph number 9 On day two of the main trials participants arrived at the laboratory between 7.45 and 8.00 am having fasted overnight (no food or drink except water) for 10 hours. On arrival at the laboratory, participants sat on a bed in a semi-supine position for 5 minutes while a cannula (BD Ven-flon, Becton-Dickinson, Helsingborg, Sweden) was inserted into an antecubital vein and a baseline blood sample was collected. Participants then consumed a prescribed test meal (see below) for breakfast. A clock was started the moment they commenced their meal and this was identified as the 0 hour. The trial continued on for nine hours during which a total of 14 (including the fasting sample), $9 \mathrm{~mL}$ venous blood samples were collected. At 4 hours, a second test meal, identical to the first, was served to participants. Participants rested throughout day two of both the control and exercise trials and hence day two of these trials was identical.

Paragraph number 10 Control of diet and exercise. The day before each main trial and on the first day of each main trial, participants recorded their food intake using a weighed food diary. Participants replicated this food intake for the next main trial. Participants were told not to consume tea, coffee, or alcohol on the day prior to and during the main trials. Participants were also asked to refrain from strenuous physical activity during the day preceding the main trials and on day 1 and day 2 of the main trials. 
Paragraph number 11 Test meals. The test meals consisted of white bread, butter, cheese, mayonnaise, crisps, chocolate milk shake powder and high fat milk. The amount of food consumed was adjusted for each participant based on their body weight and was kept constant throughout the trials. The macronutrient content of the test meal was $57 \%$ fat, $32 \%$ carbohydrate and $11 \%$ protein and each meal provided $60 \mathrm{~kJ}(14.3 \mathrm{kcal})$ per kg body mass for a $70 \mathrm{~kg}$ participant. Participants consumed each meal within 15 minutes and water was available ad libitum.

Paragraph number 12 Blood sampling. Venous blood samples were collected for the measurement of total cholesterol, high density lipoprotein (HDL) cholesterol, TAG, glucose, insulin, IL-6 and sICAM-1. Samples were collected at baseline (0 hours) and at hourly intervals thereafter for nine hours. Additional samples were collected 15 and 30 minutes after each meal i.e. at 0.25 and 0.50 hours and at 4.25 and 4.5 hours. Total cholesterol and HDL cholesterol were only measured from baseline samples; IL-6 and sICAM-1 concentrations were measured from samples collected at 0,3,6 and 9 hours; glucose, insulin and TAG were measured from all samples. Participants rested in a semi-supine position during blood sampling. Venous blood samples were drawn into pre-cooled 9 mL EDTA monovette tubes (Starstedt, Leicester, United Kingdom) and immediately centrifuged at 1500 x g (3000 revs/min) for 10 minutes in a refrigerated centrifuge (Burkard, Hertfordshire, United Kingdom) at $4^{\circ} \mathrm{C}$. The plasma supernatant was dispensed into eppendorf tubes and stored at $-80^{\circ} \mathrm{C}$ before analysis. After each blood sample collection $10 \mathrm{~mL}$ of non-heparinised saline solution ( $0.9 \%$ (v/w) sodium chloride, Baxter Healthcare Ltd, Norfolk, United Kingdom) was flushed through the cannula to maintain cannula patency. Two $\mathrm{mL}$ of blood was drawn into a syringe and discarded at the start of each blood collection to prevent sample contamination 
from saline. Haemoglobin and haematocrit values were used to estimate changes in plasma volume across the nine-hour main trial day (5).

Paragraph number 13 Blood biochemistry. Plasma total cholesterol, HDL cholesterol, TAG and glucose concentrations were determined spectrophotometrically using commercially available kits and a bench top analyser (Pentra 400, HORIBA ABX Diagnostics, Montpellier, France). Enzyme linked immuno sorbent assays (ELISA) assays were used to determine the concentrations of plasma insulin (Mercodia, Sylveniusgatan, Uppsala, Sweden), IL-6 (high sensitivity kit; Diaclone, Besançon, France) and sICAM-1 (Diaclone, Besançon, France) with the aid of a plate reader (Expert Plus, ASYS, Eugendorf, Austria). To eliminate inter assay variation, samples from each participant were analysed in the same run. Coefficients of variation for each assay were as follows: $0.7 \%$ for total cholesterol, $0.7 \%$ for HDL cholesterol, 3.0\% for TAG, $0.5 \%$ for glucose, $6.0 \%$ for insulin, $3.4 \%$ for IL-6 and $4.9 \%$ for sICAM-1.

Paragraph number 14 Statistical analysis. Data were analysed using Predictive Analytics Software version 18.0 for Windows (SPSS, Inc., Somers, NY, USA). Physical characteristics and exercise responses were compared between South Asians and Europeans using the Students t-test. Three-way repeated measures ANOVA with Bonferroni post-hoc tests was used to examine differences between trials for plasma constituents (TAG, glucose, insulin, IL-6 and sICAM-1) with the three factors being: a) trial (exercise versus control), b) ethnic group (South Asians versus Europeans) and c) time (serial measurements over 9 hours). Effect sizes (Cohen's $d$ ) were also calculated for each of these variables by dividing the differences between the mean values (exercise versus control or South Asian versus European) with the standard deviation (i.e. the average standard deviation from both trials 
and ethnic groups combined). Area under the plasma concentration versus time curve (AUC) values were calculated for TAG, glucose, insulin, IL-6 and sICAM-1 using the trapezoidal method. These values were compared using two-way repeated measures ANOVA with the two factors being trial (exercise versus control) and ethnic group (South Asian versus European). Two-way repeated measures ANOVA was also used to assess between trial and ethnic group differences for fasting plasma concentrations. Statistical significance was accepted at the $5 \%$ level. Results are presented as mean \pm SD in the text and tables and as mean $\pm S E M$ in figures.

\section{RESULTS}

Paragraph number 15 Participant characteristics. The physical characteristics of the participants are displayed in Table 1. There were no significant differences between South Asian and European participants for age, height, weight, BMI, waist circumference and resting diastolic blood pressure. Percentage body fat was higher in South Asians than Europeans while resting systolic blood pressure and $\dot{\mathrm{VO}}_{2} \max$ were lower in South Asians than in Europeans.

\section{INSERT TABLE 1 HERE}

Paragraph number 16 Responses to treadmill running. The European participants ran faster $\left(9.6 \pm 1.6\right.$ versus $\left.7.6 \pm 1.4 \mathrm{~km} \cdot \mathrm{h}^{-1} ; P<0.008\right)$ and expended more energy during the run $(3901 \pm 473$ versus $3313 \pm 623 \mathrm{~kJ} ; P<0.029)$ than the South Asian participants. There were no significant differences between groups in the $\% \dot{\mathrm{V}} \mathrm{O}_{2} \max$, average heart rate or average RPE attained during the run $\left(\% \dot{\mathrm{VO}}{ }_{2} \max : 71 \pm 2\right.$ versus $74 \pm 5 \%$; heart rate: $172 \pm 20$ versus 
$172 \pm 14$ beats.min ${ }^{-1}$; RPE: $12 \pm 1$ versus $12 \pm 2$; for European and South Asian participants respectively).

Paragraph number 17 Fasting plasma concentrations. There were significant main effects of trial for fasting total cholesterol, TAG and sICAM-1 indicating lower values on the exercise trial for fasting total cholesterol and TAG and higher values for fasting sICAM-1 (Table 2). There were significant main effects of group for fasting plasma insulin, HDL cholesterol and the ratio of total cholesterol/HDL cholesterol indicating higher insulin and total cholesterol/HDL cholesterol concentrations in the South Asian than the European participants and lower HDL cholesterol concentrations in the South Asian participants. There was a tendency $(P=0.074)$ for fasting TAG to be elevated in the South Asian participants.

INSERT TABLE 2 HERE

Paragraph number 18 Postprandial plasma concentrations. Three-way ANOVA revealed main effects of group for TAG $(P<0.001)$, insulin $(P<0.010)$ and glucose $(P<0.05)$ indicating higher postprandial TAG and insulin values in South Asian participants and higher postprandial glucose values in European participants (Figure 1). The effect sizes for these ethnic group comparisons were all large: $1.22,1.06$ and 0.85 respectively. Body fat percentage was higher in the South Asian participants than the European participants and this might confound the relationship between ethnicity and plasma concentrations, therefore, three-way ANOVA was conducted a second time with body fat added as a covariate to remove its confounding influence. Between group differences remained significant for TAG and glucose but were not significant for insulin after control for percentage body fat. 
INSERT FIGURE 1 HERE

Paragraph number 19 Three-way ANOVA revealed main effects of trial for TAG $(P<$ 0.001), IL-6 $(P<0.003)$ and sICAM-1 $(P<0.001)$ indicating that TAG (Figure 1) and IL-6 (Figure 2) concentrations were lower on the exercise trial while sICAM-1 concentrations were higher on the exercise trial (Figure 2). The effect size for these comparisons was medium for TAG (0.52) and IL-6 (0.55) and large for sICAM-1 (1.04).

\section{INSERT FIGURE 2 HERE}

Paragraph number 20 Trial and ethnic group differences were confirmed when assessing AUC values using two-way ANOVA (Table 3). Again plasma TAG and insulin concentrations were higher in South Asian participants while plasma glucose concentrations were higher in European participants. The TAG and IL-6 lowering effects of exercise were also confirmed as was the exercise induced elevation in sICAM-1. Finally, a significant trial by group interaction effect was observed for TAG indicating a greater decrease after exercise in the South Asian men than the European men (22\% versus 10\%).

INSERT TABLE 3 HERE

Paragraph number 21 Figure 3 displays the difference in the TAG AUC values between the exercise and the control trials for each participant. Negative values indicate a lowering of postprandial TAG concentration on the exercise trial. This figure demonstrates that postprandial TAG concentration was lower on the exercise trial in nine out of 10 South Asian participants and eight out of 10 European participants. It is also clear from the figure that the 
TAG lowering effect of exercise is greater in the South Asian than in the European participants.

INSERT FIGURE 3 HERE 


\section{DISCUSSION}

Paragraph number 22 The novel findings arising from this study are: 1) postprandial plasma TAG concentrations were elevated to a much greater extent in the South Asian men than in the European men in response to high fat meals; 2) exercise was equally effective if not more so for lowering postprandial plasma TAG concentrations in the South Asian men than in the European men. Another key finding arising from this study is that fasting and postprandial plasma insulin concentrations were higher in the South Asian men than in the European men. No ethnic group differences were apparent for IL-6 and sICAM-1 but postprandial plasma IL-6 concentrations were lower after exercise while postprandial sICAM-1 concentrations were higher.

Paragraph number 23 The most striking finding from this study is the clear elevation in postprandial TAG concentrations in response to high fat meals in the South Asian participants compared with the European participants. Previous studies have observed higher fasting TAG concentrations in South Asians than in White people $(1,28)$ but to our knowledge the present study is the first to report a difference in postprandial TAG concentrations between these two ethnic groups. We are aware of only one other study which has compared postprandial lipemia in South Asians and Europeans and this study did not observe a difference in the lipemic response to high fat meals although postprandial glucose and insulin concentrations were elevated in South Asians (3). A possible explanation for these different findings is that percentage body fat did not differ between ethnic groups in the study conducted by Cruz and colleagues (3) whereas body fat percentage was higher in the South Asian participants in the present study as is often the case (29). Nevertheless, between group differences in postprandial lipemia remained significant in the present study even after controlling for differences in percentage body fat. Another possible explanation for the 
disparate findings is the test meals used. The percentage fat provided in the test meals was similar between studies (52\% of energy from fat in the study by Cruz and colleagues (3) versus $57 \%$ of energy from fat in the present study) but the total amount of food consumed (which is not stated in the paper by Cruz and colleagues) may have differed.

Paragraph number 24 Another important finding from the present study is the effectiveness of running exercise for lowering postprandial TAG concentrations in the South Asian participants. The finding that postprandial TAG concentrations are lowered by a single session of prior exercise has been reported in many previous studies (for a review see Katsanos (13)) but the present study is the first to report this in South Asians. Exercise was particularly effective in the South Asian group eliciting a 22\% reduction in the TAG AUC values compared with only a $10 \%$ reduction in the European participants. This difference in the apparent effectiveness of exercise may have been due to the elevated TAG values in the South Asian participants i.e. higher values may provide a greater potential for reductions. Despite the effectiveness of exercise in the South Asian participants it is important to note that their TAG AUC values were still 33\% higher after exercise than the control trial values exhibited by the European participants. If these findings are replicated in larger samples they would suggest that South Asians are at a much higher risk of experiencing exaggerated postprandial lipemia in response to high fat meals than Europeans and this may be a contributing factor to their elevated risk of CHD. The reasons for the exaggerated postprandial lipemia in the South Asian participants are unclear. It is feasible that skeletal muscle and adipose tissue lipoprotein lipase activity is low in South Asians hence reducing their capacity to clear TAG from plasma. It is also possible that hepatic secretion of TAG (in very low density lipoproteins) is increased in South Asians in the hours after dietary fat 
intake. Both of these possibilities are speculation but they provide a clear avenue for future research.

Paragraph number 25 In addition to elevated postprandial TAG concentrations, fasting insulin concentrations were nearly six times higher and postprandial insulin concentrations were nearly three times higher in the South Asian versus the European participants. These differences suggest a degree of insulin resistance in the South Asian participants and this is consistent with the findings of Cruz and colleagues (3). Insulin resistance is thought to be a major contributor to the increased risk of type 2 diabetes and CHD experienced by those of South Asian descent $(23,28)$. Insulin resistance may also underlie the development of 'early metabolic syndrome' which has been noted in the South Asian pediatric population (7). Hyperinsulinemia resulting from insulin resistance is thought to decrease muscle lipoprotein lipase activity (19) and this would impair one of the major mechanisms for removal of TAG from blood. Thus, it is possible that the elevated postprandial lipemia exhibited by the South Asian participants in the present study is linked to their elevated plasma insulin concentrations.

Paragraph number 26 Surprisingly, and in contrast to the differences noted for insulin, we observed a small but significant difference in postprandial plasma glucose concentrations between ethnic groups with higher values in the European participants. This finding conflicts with that of Cruz and colleagues (3) who observed higher postprandial glucose concentrations in South Asian participants and also with the finding that fasting glucose concentrations are elevated in those of South Asian descent (1). Aside from this finding the other differences we observed between ethnic groups are consistent with previous research $(1,28)$ i.e. South Asian participants in the present study had a tendency for higher fasting TAG concentrations, higher 
fasting total cholesterol to HDL cholesterol ratio values and lower fasting HDL cholesterol concentrations. These findings indicate a higher risk of CHD in the South Asian participants (12).

Paragraph number 27 Interleukin-6 and sICAM-1 were assessed in the present study because both are indicative of chronic low grade inflammation which in turn is associated with an increased risk of type 2 diabetes and $\operatorname{CHD}(11,14,21)$. It has been suggested that an increased predisposition to chronic low grade inflammation, due to higher visceral and overall adiposity, might explain the elevated CHD risk in South Asians but the evidence to support this proposal is equivocal (28). We did not detect differences in IL-6 and sICAM-1 between the South Asian and European men in our study but IL-6 concentrations were suppressed the day after exercise while sICAM-1 concentrations were elevated. It is well documented that exercise causes a transient increase in the myokine IL- 6 and this is known to stimulate an anti-inflammatory cascade involving increased concentrations of IL-10 and IL-1 receptor antagonist $(18,10)$. The lower IL-6 concentrations we observed the day after exercise are possibly reflective of an anti-inflammatory effect of exercise subsequent to an initial increase in IL-6. The elevated sICAM-1 concentrations are probably related to an increased blood shear stress during exercise and it is clear that this elevation lasts for at least $24 \mathrm{~h}$ although the significance of this elevation is uncertain. Finally, we observed a small but significant reduction in fasting total cholesterol concentration the day after exercise. This is not a consistent finding in the literature and hence caution is warranted when interpreting this outcome.

Paragraph number 28 This study had three notable limitations. Firstly, the sample size is small and hence these findings require confirmation with a larger sample. Secondly, it is 
possible that the group differences observed here are confounded by the differences in percentage body fat although South Asians are known to have a higher body fat percentage for a given BMI (29) and this may explain in part their elevated CHD risk. Thirdly, most of the participants in the present study were Indian South Asians and South Asians are a heterogeneous group and hence these findings require confirmation in other South Asian groups (e.g. Bangladeshis and Pakistanis) and also in South Asian females. Future work should examine whether exaggerated postprandial lipemia occurs in all South Asian subgroups and also the extent to which exercise is effective for lowering postprandial lipemia in each subgroup.

Paragraph number 29 In conclusion; the findings of this study indicate striking elevations in postprandial lipemia in response to high fat meals in South Asian men. This study also demonstrates that running exercise is effective for lowering postprandial lipemia in South Asian men. The relationship between elevated postprandial lipemia and CHD risk in South Asians and the role of exercise in lowering postprandial lipemia and CHD risk in South Asians should be a priority for future research. 


\section{ACKNOWLEDGEMENTS}

Paragraph number 30 We would like to thank Miss Taru Saarinen and Miss Victoria Paley for help with data collection and Mr Matt Sedgwick, Mr Kevin Deighton and Dr James King for their assistance with blood biochemistry. We also extend our very sincere thanks to all of the participants for giving up their time so freely and cheerfully.

Paragraph number 31 The research was supported by the National Institute for Health Research (NIHR) Diet, Lifestyle \& Physical Activity Biomedical Research Unit based at University Hospitals of Leicester and Loughborough University. The views expressed are those of the authors and not necessarily those of the NHS, the NIHR or the Department of Health. Professor Reischak-Oliveira received funding from the Brazilian National Research Council (CNPq).

Paragraph number 32 The authors have no financial, consultant, institutional, or other relationships that might lead to bias or a conflict of interest.

Paragraph number 33 The results of the present study do not constitute endorsement by the American College of Sports Medicine. 


\section{REFERENCES}

1. Anand SS, Yusuf S, Vuksan V, Devanesan S, Teo KK, Montague PA, et al. Differences in risk factors, atherosclerosis, and cardiovascular disease bewteen ethnic groups in Canada: the Study of Health Assessment and Risk in Ethnic groups (SHARE). Lancet. 2000;356(9226):279-84.

2. Borg GA. Perceived exertion: a note on "history" and methods. Med Sci Sports. 1973;5(2):90-3.

3. Cruz ML, Evans K, Frayn KN. Postprandial lipid metabolism and insulin sensitivity in young Northern Europeans, South Asians and Latin Americans in the UK. Atherosclerosis. 2001;159(2):441-49.

4. Danaraj TJ, Acker MS, Danaraj W, Ong WJ, Yan TB. Ethnic group differences in coronary heart disease in Singapore: an analysis of necropsy records. Am Heart J. 1959;58:516-26.

5. Dill DB, Costill DL. Calculation of percentage changes in volumes of blood, plasma, and red cells in dehydration. $J$ Appl Physiol. 1974;37(2):247-48.

6. Durnin JV, Womersley J. Body fat assessed from total body density and its estimation from skinfold thickness: measurements on 481 men and women aged from 16 to 72 years. Br J Nutr. 1974;32(1):77-97.

7. Eapen D, Kalra GL, Merchant N, Arora A, Khan BV. Metabolic syndrome and cardiovascular disease in South Asians. Vasc Health Risk Manag. 2009;5:731-43.

8. Fischbacher CM, Hunt S, Alexander L. How physically active are South Asians in the United Kingdom? A literature review. J Pub Health (Oxf). 2004;26(3):250-8.

9. Frayn KN. Calculation of substrate oxidation rates in vivo from gaseous exchange. $J$ Appl Physiol. 1983;55(2):628-34. 
10. Gleeson M, Bishop NC, Stensel DJ, Lindley MR, Mastana SS, Nimmo MA. The antiinflammatory effects of exercise: mechanisms and implications for the prevention and treatment of disease. Nat Rev Immunol. 2011;11(9):607-15.

11. Hwang SJ, Ballantyne CM, Sharrett AR, Smith LC, Davis CE, Gotto Am Jr, et al. Circulating adhesion molecules VCAM-1, ICAM-1 and e-selectin in carotid atherosclerosis and incident coronary heart disease cases. The Atherosclerosis Risk In Communities (ARIC) Study. Circulation. 1997;96(12):4219-4225.

12. Joshi J, Islam S, Pais P, Reddy S, Dorairaj P, Kazmi K, et al. Risk factors for early myocardial infarction in South Asians compared with individuals in other countries. JAMA 2007;297(3):286-94.

13. Katsanos CS. Prescribing aerobic exercise for the regulation of postprandial lipid metabolism. Current research and recommendations. Sports Med. 2006;36(7):547-60.

14. Libby P, Ridker PM, Maseri A. Inflammation and atherosclerosis. Circulation. 2002;105(9):1135-43.

15. Misra A, Nigam P, Hills AP, Chadha DS, Sharma V, Deepak KK. Consensus physical activity guidelines for Asian Indians. Diabetes Technol Ther. 2012;14(1):83-98.

16. Nordestgaard BG, Benn M, Schnohr P, Tybjaerg-Hansen A. Nonfasting triglycerides and risk of myocardial infarction, ischemic heart disease, and death in men and women. JAMA. 2007;298(3):299-308.

17. Palaniappan L, Wang Y, Fortmann SP. Coronary heart disease mortality for six ethnic groups in California, 1990 - 2000. Ann Epidemiol. 2004;14(7): 499-506.

18. Petersen AM and Pedersen BK. The anti-inflammatory effect of exercise. J Appl Physiol. 2005;98(4):1154-62.

19. Pollare T, Vessby B, Lithell H. Lipoprotein lipase activity in skeletal muscle is related to insulin sensitivity. Arterioscler Thromb. 1991;11(5):1192-203. 
20. Rastogi T, Vaz M, Spielgelman D, Reddy KS, Bharathi AV, Stampfer MJ, et al. Physical activity and risk of coronary heart disease in India. Int J Epidemiol. 2004;33(4):759-67.

21. Ridker PM, Hennekens CH, Roitman-Johnson B, Stampfer MJ, Allen J. Plasma concentration of soluble intercellular adhesion molecule 1 and risks of future myocardial infarction in apparently healthy men. Lancet. 1998;351(9096):88-92.

22. Roger VL, Go AS, Lloyd-Jones DM, Benjamin EJ, Berry JD, Borden WB. Heart disease and stroke statistics - 2012 update: a report from the American Heart Association. Circulation. 2012;125(22):e2-220.

23. Sandeep S, Gokulakrishnan K, Deepa M, Mohan V. Insulin resistance is associated with increased cardiovascular risk in Asian Indians with normal glucose tolerance - The Chennai Urban Rural Epidemiology Study (CURES-66). J Assoc Physicians India. 2011;59:480-4.

24. Scarborough P, Bhatnagar P, Wickramasinghe W, Smolina K, Mitchell C, Rayner M. UK coronary heart disease statistics 2009-2010. British Heart Foundation 2010; [cited 2012 Jun 27]. Available from:

http://www.bhf.org.uk/search/results.aspx?m=simple\&q=coronary+heart+disease\&subco $\underline{\mathrm{n}=\mathrm{BHF} \_ \text {main_site. }}$

25. Sheth T, Nair C, Nargundkar M, Anand S, Yusuf S. Cardiovascular and cancer mortality among Canadians of European, South Asian and Chinese origin from 1979 to 1993: an analysis of 1.2 million deaths. CMA J. 1999;161(2):132-8.

26. Siri WE. The gross composition of the body. Adv Biol Med Phys. 1956;4:239-80.

27. Taylor HL, Buskirk E, Henschel A. (1955). Maximal oxygen uptake as an objective measure of cardio-respiratory performance. J Appl Physiol. 1955;8(1):73-80.

28. Tziomalos K, Weerasinghe CN, Mikhailidis DP, Seifalian AM. Vascular risk in South Asians. Int J Cardiol. 2008;128(1):5-16. 
29. Wang J, Thornton JC, Russell M, Burastero S, Heymsfield S, Pierson RN Jr. Asians have lower body mass index (BMI) but higher percent body fat than do whites: comparisons of anthropometric measurements. Am J Clin Nutr. 1994;60(1):23-8.

30. Wild SH, Fischbacher C, Brock A, Griffiths C, Bhopal R. Mortality from all causes and circulatory disease by country of birth in England and Wales 2001-2003. J Public Health (Oxf). 2007;29(2):191-8.

31. Williams ED, Stamatakis E, Chandola T, Hamer M. Assessment of physical activity levels in South Asians in the UK: findings from the Health Survey for England. $J$ Epidemiol Community Health. 2011;65(6):517-21.

32. Williams ED, Stamatakis E, Chandola T, Hamer M. Physical activity behaviour and cornary heart disease mortality among South Asian people in the UK: an observational longitudinal study. Heart. 2011;97(8):655-9.

33. World Health Organisation. Cardiovascular disease: fact sheet n.317.September 2011; [cited 2012 Jun 27]. Available from: http://www.who.int/mediacentre/factsheets/fs317/en/index.html.

34. Yates T, Davies MJ, Gray LJ, Webb D, Henson J, Gill JM, et al. Levels of physical activity and relationship with markers of diabetes and cardiovascular disease risk in 5474 white European and South Asian adults screened for type 2 diabetes. Prev Med. 2010;51(3-4):290-294. 


\section{FIGURE CAPTIONS}

FIGURE 1: Mean \pm (SEM) postprandial plasma triacylglycerol (top panel), glucose (middle panel) and insulin (bottom panel) concentrations measured on day two of the exercise and control trials for South Asian $(n=10)$ and European $(n=10)$ men. Data were analysed using three-way repeated measures ANOVA. There were significant main effects of trial $(P=$ $0.001)$ for triacylglycerol and significant main effects of ethnicity for triacylglycerol $(P=$ $0.001)$, glucose $(P=0.043)$ and insulin $(P=0.010)$. There was also a trial $\mathrm{x}$ ethnicity effect for triacylglycerol $(P=0.031)$.

FIGURE 2: Mean \pm (SEM) postprandial plasma concentrations of soluble intercellular adhesion molecule-1 (sICAM-1) and interleukin-6 (IL-6) measured on day two of the exercise and control trials for South Asian $(n=10)$ and European $(n=10)$ men. Data were analysed using three-way repeated measures ANOVA. A main effect of trial was observed for sICAM-1 $(P<0.001)$ and IL-6 $(P=0.003)$. There were no main effects for ethnicity.

FIGURE 3: Individual changes (exercise minus control) in the total area under the TAG concentration versus time curve in response to the 60 min treadmill run for South Asian $(n=10)$ and European $(n=10)$ men. Negative values indicate lower concentrations on the exercise trial. 
Table 1. Participant characteristics.

\begin{tabular}{|c|c|c|c|c|c|c|c|}
\hline \multirow{2}{*}{$\begin{array}{l}\text { Variable } \\
\text { Age (years) }\end{array}$} & \multicolumn{3}{|c|}{$\begin{array}{l}\text { South Asians } \\
\qquad(\mathrm{n}=\mathbf{1 0})\end{array}$} & \multicolumn{3}{|c|}{$\begin{array}{l}\text { Europeans } \\
\qquad(\mathbf{n}=\mathbf{1 0})\end{array}$} & \multirow{2}{*}{\begin{tabular}{|c|}
$\boldsymbol{P}$ value \\
0.259
\end{tabular}} \\
\hline & 22.3 & \pm & 1.3 & 23.2 & \pm & 2.0 & \\
\hline Height $(\mathrm{cm})$ & 173.0 & \pm & 5.7 & 177.0 & \pm & 6.0 & 0.133 \\
\hline Weight (kg) & 76.3 & \pm & 9.1 & 79.2 & \pm & 8.6 & 0.471 \\
\hline Body mass index $\left(\mathrm{kg} \cdot \mathrm{m}^{-2}\right)$ & 25.4 & \pm & 2.5 & 25.2 & \pm & 1.6 & 0.818 \\
\hline Body fat $(\%)$ & 23.0 & \pm & 4.4 & 16.4 & \pm & 4.2 & 0.003 \\
\hline Waist circumference $(\mathrm{cm})$ & 82.8 & \pm & 4.9 & 80.0 & \pm & 3.3 & 0.144 \\
\hline Resting SBP (mm Hg) & 128 & \pm & 8 & 138 & \pm & 11 & 0.032 \\
\hline Resting DBP (mm Hg) & 75 & \pm & 8 & 76 & \pm & 6 & 0.757 \\
\hline$\dot{\mathrm{VO}}{ }_{2} \max \left(\mathrm{mL} \cdot \mathrm{kg}^{-1} \cdot \mathrm{min}^{-1}\right)$ & 48.2 & \pm & 7.3 & 56.6 & \pm & 6.7 & 0.015 \\
\hline
\end{tabular}

Values are mean \pm SD. Means were compared using student's t-test. SBP, systolic

blood pressure; DBP, diastolic blood pressure; $\dot{\mathrm{VO}}_{2}$ max, maximal oxygen uptake. 
Table 2. Fasting plasma concentrations on day two of the main trials.

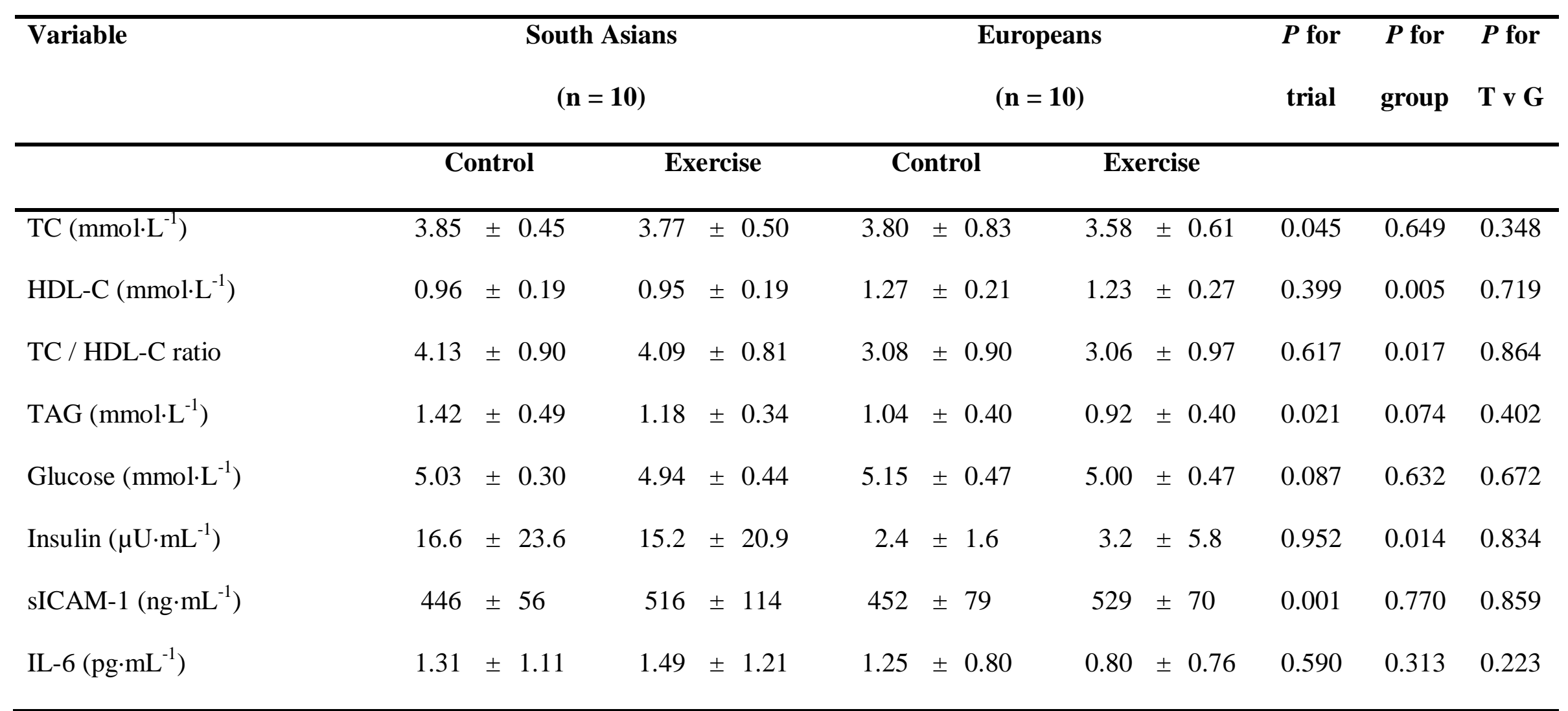

Values are mean \pm SD. Comparisons were made using two-way ANOVA. T, trial (exercise versus control); G, group (South Asian

versus European); TC, total cholesterol; HDL-C, high density lipoprotein cholesterol; TAG, triacylglycerol; sICAM-1, soluble intercellular adhesion molecule-1; IL-6, interleukin-6. 
Table 3. Area under the postprandial concentration versus time curve values on day two of the main trials.

\begin{tabular}{|c|c|c|c|c|c|c|c|}
\hline \multirow[t]{2}{*}{ Variable } & \multicolumn{2}{|c|}{$\begin{array}{l}\text { South Asians } \\
\qquad(\mathrm{n}=10)\end{array}$} & \multicolumn{2}{|c|}{$\begin{array}{c}\text { Europeans } \\
\qquad(\mathbf{n}=\mathbf{1 0})\end{array}$} & \multirow[t]{2}{*}{$\begin{array}{l}P \text { for } \\
\text { trial }\end{array}$} & \multirow[t]{2}{*}{$\begin{array}{l}P \text { for } \\
\text { group }\end{array}$} & \multirow[t]{2}{*}{$\begin{array}{l}P \text { for } \\
T \text { v G }\end{array}$} \\
\hline & Control & Exercise & Control & Exercise & & & \\
\hline TAG $\left(\mathrm{mmol} \cdot \mathrm{L}^{-1} 9 \mathrm{~h}\right)$ & $26.1 \pm 7.1$ & $20.2 \pm 5.2$ & $15.2 \pm 3.9$ & $13.7 \pm 3.7$ & 0.001 & 0.001 & 0.026 \\
\hline Glucose $\left(\mathrm{mmol} \cdot \mathrm{L}^{-1} 9 \mathrm{~h}\right)$ & $43.0 \pm 4.8$ & $43.8 \pm 5.2$ & $47.7 \pm 4.4$ & $48.5 \pm 5.4$ & 0.307 & 0.037 & 0.967 \\
\hline Insulin $\left(\mu \mathrm{U} \cdot \mathrm{mL}^{-1} 9 \mathrm{~h}\right)$ & $419 \pm 326$ & $341 \pm 215$ & $151 \pm 77$ & $133 \pm 76$ & 0.126 & 0.012 & 0.331 \\
\hline sICAM-1 (ng.mL $\left.{ }^{-1} 9 \mathrm{~h}\right)$ & $4125 \pm 643$ & $4960 \pm 1119$ & $4233 \pm 433$ & $4921 \pm 511$ & $<0.001$ & 0.900 & 0.679 \\
\hline IL-6 (pg.mL $\left.{ }^{-1} 9 \mathrm{~h}\right)$ & $16.1 \pm 6.9$ & $13.9 \pm 6.4$ & $14.1 \pm 5.5$ & $9.3 \pm 6.0$ & 0.004 & 0.212 & 0.249 \\
\hline
\end{tabular}

Values are mean \pm SD. Comparisons were made using two-way ANOVA. T, trial (exercise versus control); G, group (South Asian versus

European); TAG, triacylglycerol; sICAM-1, soluble intercellular adhesion molecule-1; IL-6, interleukin-6. 
Figure 1

Click here to download high resolution image
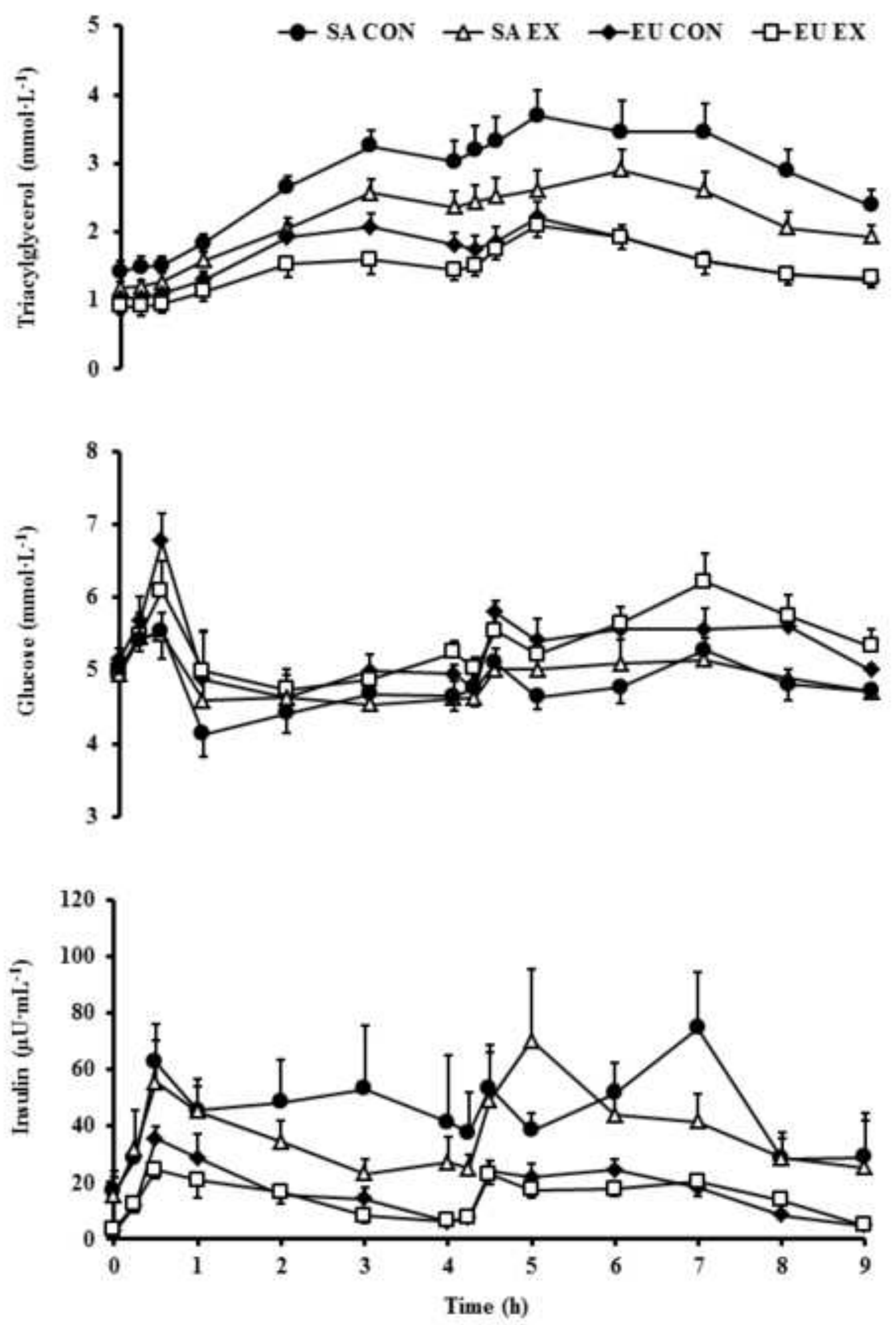
Click here to download high resolution image
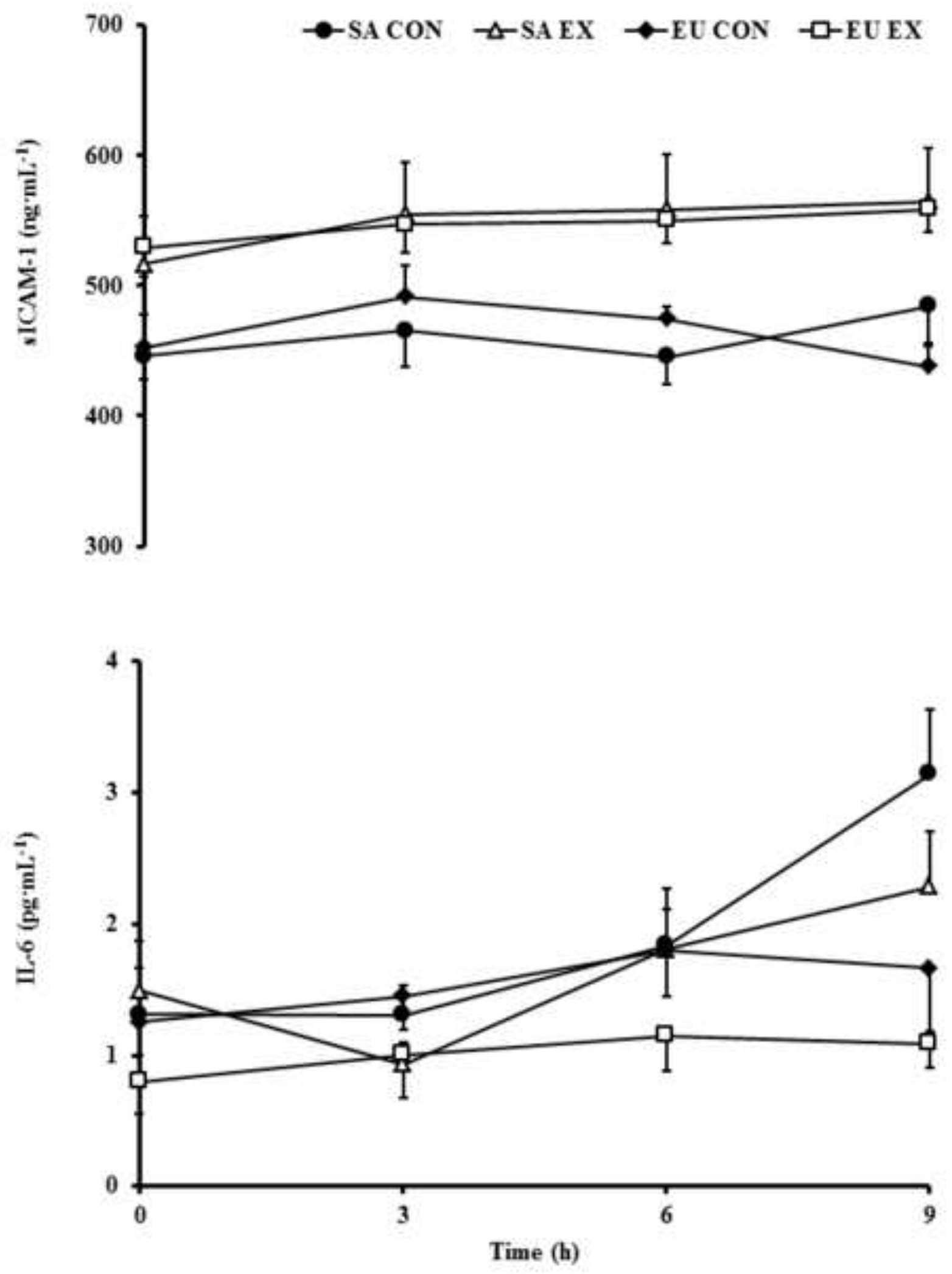


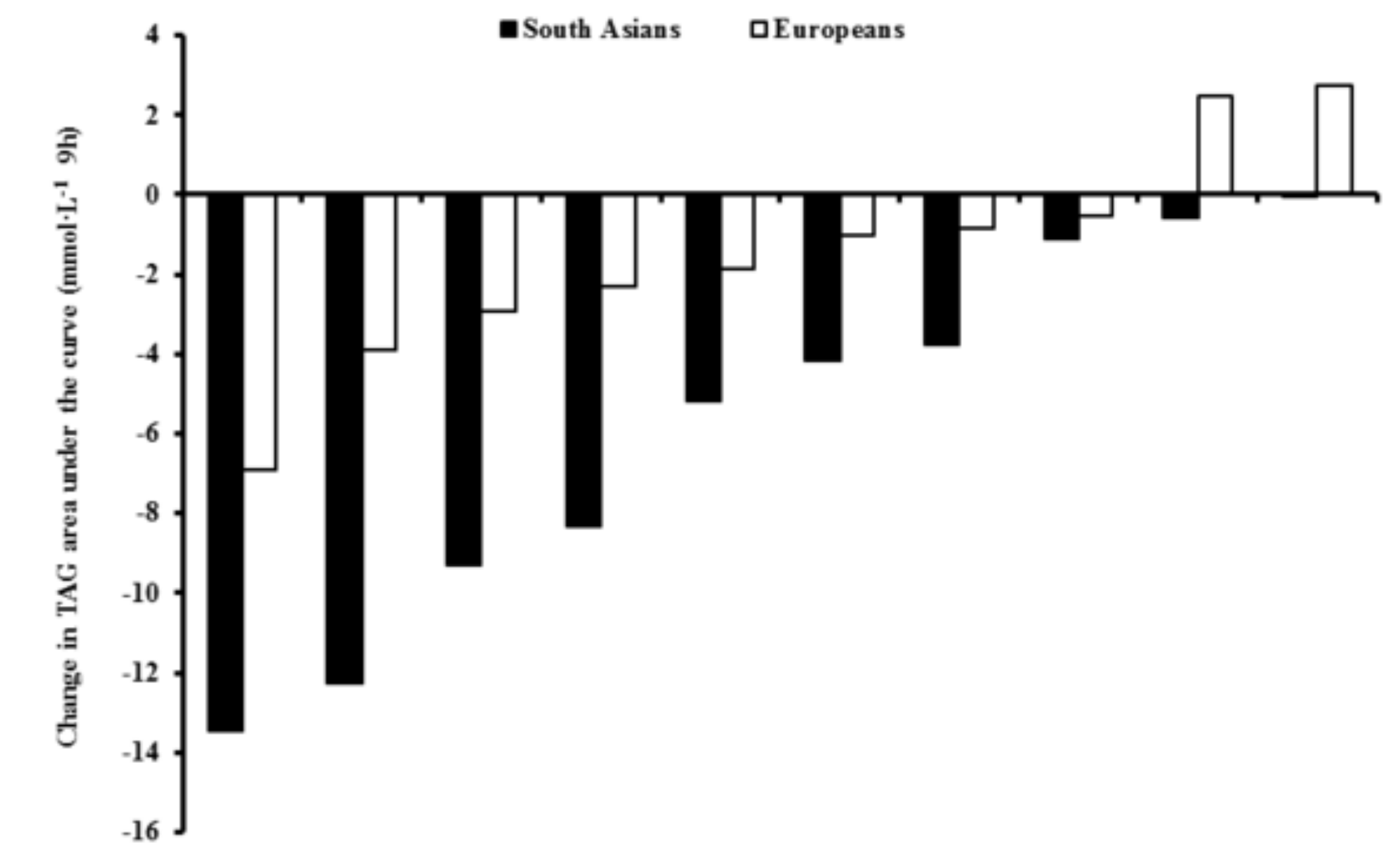

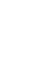

